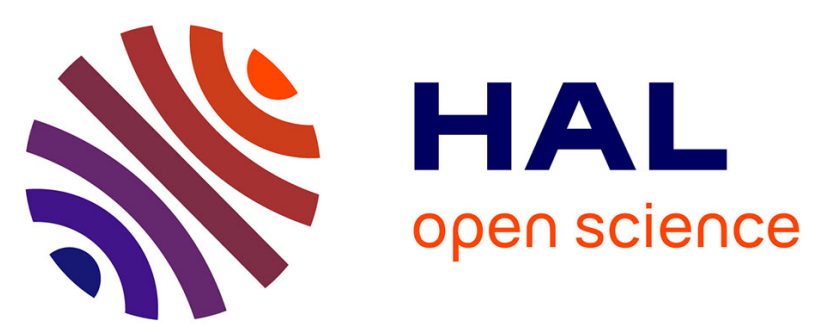

\title{
Plant translocations in Europe and the Mediterranean: Geographical and climatic directions and distances from source to host sites
}

Mohamed Diallo, Sébastien Ollier, Anaël Mayeur, Juan Fernandez-Manjarres, Alfredo García- Fernández, José María Iriondo, Anne-Charlotte Vaissière, Bruno Colas

\section{To cite this version:}

Mohamed Diallo, Sébastien Ollier, Anaël Mayeur, Juan Fernandez-Manjarres, Alfredo García- Fernández, et al.. Plant translocations in Europe and the Mediterranean: Geographical and climatic directions and distances from source to host sites. Journal of Ecology, 2021, 109 (6), pp.2296-2308. 10.1111/1365-2745.13609 . hal-03431422

\section{HAL Id: hal-03431422 \\ https://hal.science/hal-03431422}

Submitted on 19 Nov 2021

HAL is a multi-disciplinary open access archive for the deposit and dissemination of scientific research documents, whether they are published or not. The documents may come from teaching and research institutions in France or abroad, or from public or private research centers.
L'archive ouverte pluridisciplinaire $\mathbf{H A L}$, est destinée au dépôt et à la diffusion de documents scientifiques de niveau recherche, publiés ou non, émanant des établissements d'enseignement et de recherche français ou étrangers, des laboratoires publics ou privés. 
1 Title page

2

3 Plant translocations in Europe and the Mediterranean: geographic and climatic directions

4 and distances from source to host sites.

5

6 - Authors and affiliations-

7 Mohamed Diallo ${ }^{1}$, Sébastien Ollier ${ }^{1}$, Anaël Mayeur ${ }^{1}$, Juan Fernandez-Manjarres ${ }^{1}$, Alfredo García-

8 Fernández $^{2}$, José María Iriondo ${ }^{2}$, Anne-Charlotte Vaissière ${ }^{1}$ and Bruno Colas ${ }^{1}$

9

$10{ }^{1}$ Ecologie, Systématique et Evolution, Université Paris-Sud/CNRS/AgroParisTech, Université

11 Paris Saclay, France.

$12{ }^{2}$ Dept. Biologia y Geologia, Fisica y Quimica Inorganica, Universidad Rey Juan Carlos, Spain.

14 - Correspondence author-

15 Bruno Colas, Ecologie, Systématique et Evolution, Bâtiment 360, rue du Doyen André Guinier,

1691400 Orsay, France. E-mail: bruno.colas@u-psud.fr 


\section{Abstract}

21 Although the number of plant translocations has been rapidly increasing for two decades, no study

22 is available to date that examines the directions and distances of plant displacements, which is

23 essential (though not sufficient) information for considering translocations as a management tool

24 to enable species to cope with the consequences of climate change. In this paper we study the

25 geographic and climatic directions and distances from source to host sites in 638 source-and-host

26 site pairs of plant translocations that aimed to achieve viable populations in the last decades in the

27 Western Palearctic (Europe and the Mediterranean). Translocation distances ranged from 0 to 661

$28 \mathrm{~km}$, but were generally short, most (82\%) being less than $25 \mathrm{~km}$, due to both ecological

29 considerations and legal and administrative constraints. The host sites were not preferentially

30 located in any geographic direction or in any altitude relative to the source sites. In contrast, on a

31 climate compass constructed from a principal component analysis of seven bioclimatic variables,

32 the host sites were slightly, but significantly, under colder climatic conditions than the source sites.

33 This observation appears to be more the consequence of an effort to counteract already felt effects

34 of climate change than to anticipate future changes. The climatic distance between source sites and

35 actual host sites was generally smaller than between source sites and randomly selected host sites

36 at a given distance or within a given geographical area, which may be the result of a desire to

37 minimise climatic differences or differences in other ecological factors correlated with climatic

38 differences.

39 Synthesis. This study is the first to compare, geographically and climatically, the source sites of

40 biological material and the host sites in translocations of wild plant species to obtain viable

41 populations. Past translocations are in line with mitigating the consequences of global warming on 
42 plant species, because the host sites were in slightly cooler conditions than the source sites. Despite 43 this, climate considerations seem to have been little taken into account in plant translocation 44 projects and will certainly have to be much more so in a future with rapid anthropogenic climate 45 change.

46

47 Keywords

48 reintroduction; reinforcement; plant conservation; biodiversity management; climate change 49 mitigation; climate distance; bioclimatic variable 


\section{Introduction}

52 Species translocations are increasingly used to restore communities or preserve or improve the

53 conservation status of species (e.g., Soorae, 2018; Silcock et al., 2019). Indeed, anthropogenic

54 pressures on natural habitats, due to agriculture, industry, transport and urbanisation, have led to a very high degree of fragmentation of natural habitats, which continues to increase, notably in

Europe (European Environment Agency, 2011). Habitat fragmentation has two components:

57 habitat patches are smaller and the distance between them is greater. The consequences for species living in these fragmented habitats are that population sizes are smaller and migration rates between

59 populations are reduced. Small populations are more likely to suffer from demographic 60 stochasticity, environmental stochasticity, Allee effects, inbreeding depression and low 61 evolutionary potential due to loss of genetic variation, and accumulation of deleterious mutations 62 (Lacy, 2000; Frankham, 2005). They then fall more easily into a dynamic that leads them to extinction (extinction vortex, Biere et al., 2002; Fagan \& Holmes, 2006). When they are isolated,

64 populations do not benefit from demographic or genetic rescue (Vilà et al., 2003; Hufbauer et al., 2015) to restore their viability by receiving individuals or gametes from neighbouring populations through migration. Although adaptive responses can mitigate its deleterious effects in a number of examples (Colas et al., 2004), habitat fragmentation is a major factor in altering the dynamics of metapopulations and the conservation status of species (Hanski et al., 2013; see also Fahrig, 2017 and Fletcher et al., 2018, for a controversy on the effects of habitat fragmentation on biodiversity).

Climate change is an added threat. In response to warming, species must adapt or migrate

71 polewards, or to higher altitudes, or to more shaded slopes (Thomas et al. 2004; Lenoir et al., 2008;

72 Lavergne et al., 2010; Urban, 2015; Román-Palacios \& Wiens, 2020). However, in a context of 
73 habitat fragmentation, small populations have a reduced evolutionary potential to adapt to new

74 conditions and fewer opportunities to reach new favourable habitat patches because of their

75 isolation. Habitat fragmentation and climate change therefore have synergistic effects on the

76 viability of metapopulations (Brook et al., 2008), especially for plants whose dispersal is generally

77 limited (Riba et al., 2005; Dullinger et al., 2015).

In this context, species translocations can allow (i) either demographic and genetic rescues

79 that prevent the extinction of existing populations (reinforcements), or (ii) the colonisation of

80 favourable patches that are difficult to reach by natural dispersal (reintroductions in formely

81 occupied sites or creation of populations in new sites within or beyond the extent of occurrence of

82 the species). Plant translocations are now a common practice (e.g., Colas et al., 1997; Noël et al.,

83 2011; Laguna et al., 2016). The main reasons for conducting translocation operations, beyond

84 reaching the viability of the translocated populations, are the improvement of the conservation

85 status of threatened species and the ecological restoration of degraded ecosystems. These actions

86 can be underpinned by a legal framework (e.g. nature protection measures in the context of

87 construction or development projects) or be triggered on a voluntary basis (e.g., cause defended by

88 a non-profit organisation).

With climate change as an important concern for species conservation (Thomas et al., 2004;

90 Thuiller et al., 2005; Bellard et al., 2012; Urban, 2015), translocations represent an opportunity for

91 practitioners to contribute to the migration of populations towards the poles, or higher up in

92 altitude, to cooler climatic conditions, thus mitigating the deleterious effects of warming (Fahselt,

93 2007; Brooker et al., 2011; Aitken \& Whitlock, 2013). Review articles on plant translocations have

94 focused on an assessment of the success of translocations, and the factors determining that success

95 (Menges, 2008; Godefroid et al., 2011; Dalrymple et al., 2011; Silcock et al., 2019), although the 
96 criteria for success are themselves a subject of debate (Robert et al., 2015a, 2015b; Haskins, 2015;

97 Seddon, 2015; Shier, 2015). Curiously, no studies are available that examine the geographic and

98 climatic differences between the natural origins of translocated plant material and its final

99 destination. This is probably because relatively few data on plant translocations are readily

100 available in the scientific literature, and the grey literature describing them is widely scattered. In

101 particular, data regarding the location of natural populations from which the plant material used for

102 the translocation process was originally harvested are difficult to find. In scientific articles and

103 progress reports, information about botanical institutions that have stored or propagated plant

104 material, and how they did it, is more frequent than information about the original natural 105 populations.

Here, we propose to study the locations of source and host sites involved in translocations 107 in the Western Palearctic (Europe and Mediterranean basin), by searching for geographical 108 information on translocated populations of plants recorded in the TransLoc database 109 (http://translocations.in2p3.fr). This will allow us to examine translocation distances and compare 110 the geographical position and climatic conditions between the natural origin and the final 111 destination of the plant material, regardless of the time it has spent ex situ (e.g. in cold storage or 112 in cultivation) and the number of generations between the initial harvest and the final sowing or 113 transplanting in natura.

114 We will specifically ask the following questions: (i) What is the distribution of plant 115 translocation distances? (ii) Are the geographical directions of plant translocations randomly 116 distributed around the compass rose? (iii) Do plant translocations generally occur to sites with 117 climatic conditions that are different (e.g. colder) from the natural origins of the plant material? 
118 (iv) For given translocation distances, are plant translocations preferably to host sites with climatic

119 conditions more similar to the source sites than is randomly expected for these distances?

122 Materials and methods

124 -Data collection-

127 Translocated plant and lichen populations were identified using the TransLoc database

128 (http://translocations.in2p3.fr). This database has been developed using data on plant, lichen and

129 animal translocations in the Western Palearctic from ca. 1980 to 2019. The TransLoc database has

130 a population basis. This means that the basic unit on which information is collected is a biological

131 entity, the population, and not a restoration programme or action plan (such as the Plans Nationaux

132 d'Action in France or Species Recovery Programmes in the UK), which may involve several

133 species, or several sites for a species. A population is defined as a group of conspecific organisms

134 that occupy a defined geographic area and between which ecological and reproductive interactions

135 are more frequent than between them and other populations of the same species (Futuyma, 1986,

136 p.554-555). To be included in the database, a population must contain a significant proportion of

137 individuals that have been deliberatly displaced (or the descendants of such individuals) in order

138 to achieve population viability. The taxon must be identified and the date of translocation and the

139 location of the population's host site must be known with some precision. The necessary objective 
140 of establishing a viable population or increasing the viability of an existing one may be

141 accompanied by other objectives such as improving the conservation status of the species on a

142 global or regional scale, or contributing to the restoration of a community, or a utilitarian objective

143 for human well-being.

144 For every translocated population identified as explained above, optional information is

145 collected when available. This information relates to the (i) context of the translocation (e.g.,

146 organizations involved, rationale for translocation, possible causes of taxon decline), (ii) type of

147 translocation (reinforcement or reintroduction or creation of a population in a new site), (iii)

148 characteristics of the host site (e.g., habitat type, distance to nearest population), (iv) biological

149 material used (e.g., location of original population, diversity of life cycle stages), (v) various

150 technical aspects (e.g., time spent ex situ in cold storage, greenhouse or garden, habitat preparation,

151 post-translocation management), (vi) post-translocation monitoring effort (e.g., frequency and

152 types of observations), and (vii) translocation results (e.g., population size, consequences on

153 ecosystems). The sources of information are peer-reviewed scientific articles, books, theses,

154 conference papers, presentations, reports, newspaper articles, maps, webpages, interviews, and

155 personal communications.

--Geographic data--

158 For every plant and lichen population in the database, we sought to locate the natural populations 159 from which the biological material originated. For every identified original population, we 160 delimited the geographical area in which it was located according to the available information. For 161 some populations, this area was a round buffer of variable size around a fairly precise point such 162 as a hamlet, a peak, or a cape, and for others it corresponded to a well-defined territory of variable 
163 size and shape such as an island, a pond, a nature reserve, a municipal territory, a province, etc.

164 We then standardized all locations of original populations (henceforth, source site) by determining 165 the latitude and longitude of the central point of the delimited area and by the maximum possible 166 error between these coordinates and the actual position of the sampled population (the largest 167 distance between the central point and the edge points of the area). These data were obtained by 168 cross-referencing information from the documents relating to each translocation, Google Earth 169 (Google Inc., 2017), the Database of Global Administrative Areas (GADM, 2018), and any 170 document containing geographic information on the areas under consideration (e.g. web pages of 171 municipalities, nature reserves, etc.). Similar work has been carried out to specify the location of 172 the translocated populations (henceforth, host sites) as accurately as possible. We did not consider 173 the ex situ locations where the biological material was kept or propagated between harvest from a 174 natural population and transfer to the host site.

We were able to identify at least one source site for 613 populations among the 877 176 translocated populations of plants (867) and lichens (10) in the TransLoc database. This allowed 177 us to generate a first array of 771 pairs of source and host sites, each associated with a taxon. From 178 this array we removed all pairs of marine populations (of Posidonia oceanica, Zostera marina, and 179 Z. noltii) because the analyses on the climatic differences between source and host sites (see below) were based on terrestrial data. We also removed pairs of sites for which the maximum possible error in the coordinates of either the source or host site was likely to result in an excessive bias in the geographic or climatic distances between sites (see Supporting Information Figure S1). After 183 these exclusions, the final array used for the analyses contained 638 pairs of source and host sites 184 for 280 different taxa. In the final array, the maximum possible error was on average $1.81 \mathrm{~km}$ for 185 hosts sites (range 0.1-11.0 km) and $2.31 \mathrm{~km}$ for source sites (range 0.1-14.0 km). 
187 origin of biological material translocated to several populations of the same species or of different 188 species. Likewise, host sites could appear several times when they hosted translocated populations 189 of several species or one population with several source sites. Source and host sites of one source190 and-host site pair could be the same in the following cases: (i) when the translocation process 191 consisted of a reintroduction attempt using biological material harvested from that specific locality 192 prior to local extirpation, (ii) when the translocation process consisted of trying to reinforce an 193 existing population with biological material previously harvested from the same population but 194 propagated or cultivated ex situ to increase the number of individuals or make it pass a critical stage 195 in the life cycle; (iii) when the two source and host sites were separate in the same area but the 196 position of one of the sites could not be determined with sufficient precision, in which case the 197 coordinates of both original and host sites have been degraded to the scale of the area (e.g., a 198 municipal territory).

We downloaded historical climate data with a 30-second spatial resolution $\left(\sim 1 \mathrm{~km}^{2}\right)$ from the 202 WordClim database version 2.1 (https://www.worldclim.org/data/worldclim21.html, Fick \& Hijmans, 2017) using the dismo package of $\mathrm{R}$ (R Core Team, 2019). This database is the result of 204 work initiated by Nix (1986) for the BIOCLIM package and its subsequent developments (Booth et al., 2014). It compiles monthly climate data from multiple weather stations and makes available 206 bioclimatic variables, i.e. climate data believed to be biologically significant, the detailed 207 description of which is available in O'Donnell and Ignizio (2012). We have selected seven 208 bioclimatic variables based on climate averages for every month across the 1970-2000 span of 
years ('climate normals' sensu O’Donnell \& Ignizio, 2012). They reflect the climatic means,

210 variability, and extremes that we thought were important for plants in temperate and Mediterranean

211 regions. These variables are (naming after Fick \& Hijmans, 2017, with additional information in

212 brackets) $\mathrm{BIO} 1=$ annual mean temperature, $\mathrm{BIO} 4=$ temperature seasonality (standard deviation

213 of monthly temperature averages $\mathrm{x} 100$ ), BIO5 = max temperature of warmest month (monthly

214 mean of daily maximum temperatures of the warmest month), BIO6 = min temperature of coldest

215 month (monthly mean of daily minimum temperatures of the coldest month), BIO12 = annual

216 precipitation, $\mathrm{BIO} 15$ = precipitation seasonality (coefficient of variation of monthly precipitation

217 totals), $\mathrm{BIO} 18=$ precipitation of warmest quarter (total precipitation over the warmest 3-month

218 time span).

\section{-Data analyses-}

--Geographic distances and directions--

223 All source and host sites were mapped and the geographic distance between sites for each pair of

224 source and host sites was calculated using the distGeo() function of the geosphere package of R.

225 The normality and variance homogeneity of translocation distances were improved applying the

$226 x^{\prime}=\log \left(x^{1 / 3}+1\right)$ transformation. Each host site was plotted on a compass according to the

227 differences in latitude and longitude compared to the source sites, using the tranformed distances

228 and grouping all the source sites into a single central point. We tested whether the translocations

229 were significantly directed towards one cardinal point by bootstrapping the differences in latitude

230 and longitude between sites and observing if the zero value was included within the $95 \%$ - 
231 confidence interval. All tests were done after removing site pairs with a geographical distance of 232 zero, and prohibiting repetition of site pairs to avoid giving much weight to translocation 233 programmes involving several species with the same source site on the one hand, and the same host 234 site on the other hand. Differences in altitude were tested in the same way.

237 Every bioclimatic variable was standardized to have a mean of 0 and a standard deviation of 1 over 238 the whole set of pixels available in the study area (Western Palearctic). Then, for each bioclimatic 239 variable and each pair of sites, a difference was calculated as the host site value minus the source 240 site value. A climatic distance for each pair of sites was calculated as the Euclidian distance 241 between source and host sites in the seven-dimensional space of normalized climatic variables. 242 This distance was transformed to the power $1 / 7$ to normalize its distribution. We examined the 243 correlation between Euclidian climatic and geographic distances on transformed data.

To understand the climate gradients of the study area, we applied a principal component analysis (PCA) on standardized data of the seven bioclimatic variables from the WorldClim

246 database over the entire study area (Western Palearctic). This allowed us to summarize the climate 247 data on two principal axes and visualize the largest fraction of each climatic distance between sites on a two-dimensional factorial map. By grouping the climatic coordinates of all source sites into a

249 single central point, we were able to build a climatic compass (similar to the geographic compass 250 described above) where the climatic positions of the host sites were plotted according to their total 251 climatic distance (transformed data) from the source sites and a direction defined by the first two 252 axes of the factorial map. We then tested whether the translocations significantly tended to any 253 direction of the factorial axes by bootstrapping the differences in coordinates in the first and second 
254 axes between source and host sites, as for latitudes, longitudes, and altitudes, and observing if the 255 zero value was included within the 95\%-confidence intervals.

258 To examine whether the choice of host sites was made so as to somewhat minimize their climatic

259 distance from the source sites, we compared the observed Euclidian climatic distances to the

260 climatic distances between the source sites and random geographic points obtained in two different 261 ways (see Supporting Information Figure S2). First, for each pair of source and host sites separated 262 by more than $5 \mathrm{~km}$, we simulated one hundred random points around the source site, at a distance 263 equal to that where the host site was $\pm 5 \%$, in any direction. The (transformed) climatic distance 264 between the source site and each simulated geographic point was recorded. We then determined 265 the proportion of simulated points that gave a climatic distance lower than that of the true host site. 266 Over all pairs of sites, this allowed us to see whether, for a given geographical distance, the 267 geographical direction chosen between the source and host tended to minimize their climatic 268 difference from what was expected with a random choice.

Secondly, we simulated one hundred random points around every host site within a radius equal to 0.25 times the distance separating source and host sites. Again, for each pair of source and

271 host sites separated by more than $5 \mathrm{~km}$, the climatic distance between the source site and each 272 simulated geographic point was recorded, and the proportion of simulated points that gave a 273 climatic distance lower than that of the true host site was determined. Over all pairs of sites, this 274 allowed us to see if, in a given direction from the source site, the choice of the host site tended to 275 reduce the climatic difference with the source site compared to what was expected with a random 276 choice around the chosen site (within an area proportional to the square of the distance separating 
277

278

279

280

281

282 Results

283

284

285

286

287

288

289

290

291

292

293

294

295 296 Figure S4.

297

298

source and host sites). For both types of simulations, Student's t-tests allowed us to test whether the proportion of simulated geographic points with a lower climatic distance from the source site than the true host site was significantly less than $50 \%$.

\section{-Geographic distances and directions-}

Source and host sites were located in fifteen different countries (Fig. 1). Translocation distances, from source to host sites, ranged from 0 to $661 \mathrm{~km}$ (mean: $28.9 \mathrm{~km}$, median: $2.7 \mathrm{~km}) ; 202$ (32\%) were at less than $1 \mathrm{~km}, 320(50 \%)$ were from $1 \mathrm{~km}$ to $25 \mathrm{~km}$, and $116(18 \%)$ were at longer distances (see Supporting Information Figure S3 for the distribution of translocation distances). Translocation distances were longer in the northernmost operations than in the southernmost operations (see Supporting information Tables S1-S5 for details on geographic data). The host sites were distributed quite homogeneously on the geographic compass (Fig. 2), suggesting no preferred direction from source to host sites. This was confirmed by the bootstrap results on the differences in latitude and longitude between the source and host sites showing that the confidence intervals of the means of both differences included zero (Table 1). The difference in altitude was not significant either. The distributions of bootstrap means are available in Supporting Information

\section{-Climatic distances and directions-}


299 The correlation between the Euclidian climatic and the geographic distances separating source and 300 host sites was positive and highly significant (Fig. 3, $r$ (Pearson) $\left.=0.91 ; P<10^{-3}\right)$. Climatic distances 301 are distributed similarly to geographic distances, with a bundle of short distances, where source 302 and host sites often fall within the same climatic pixel, a group of medium distances distributed 303 more or less normally, and a group of long distances with a near log-normal distribution (Fig. 3).

304 As with geographic distances, climatic distances were greater in the northernmost operations than 305 in the southernmost operations (Supporting information Table S6). representing two important climate gradients for plants (Fig. 4). The first axis was related to a temperature gradient roughly oriented north-south. The second axis was related to an oceanic versus continental gradient roughly oriented west-east. The position of the host sites on the climate map was mainly in places where the climate was more oceanic than average in the Western Palearctic (negative coordinates on axis 2, Fig. 4). 314 towards colder situations, than on the right side (194 versus 152, Fig. 5). Consequently, the 315 bootstrap analysis showed that the mean difference in coordinates of the host sites on the first 316 factorial axis was significantly negative (Table 1). No significant difference was observed on axis 3172 (oceanic-continental gradient). The distribution of bootstrap means is available in Supporting 318 Information Figure S4. 
322 distance between the source and host sites $\pm 5 \%$ ), the proportion of random points that resulted in 323 a lower climatic distance value than the selected host site was significantly less than $50 \%$ when the 324 host sites were located within $50 \mathrm{~km}$ of the source sites (Fig.6). When the host sites were located 325 more than $50 \mathrm{~km}$ from the source sites, the proportion of random sites that gave a value of climatic 326 distance less than that of the chosen host site did not differ from 50\%. Thus, compared to random 327 choices, the observed geographical directions from source sites to host sites tended to minimize 328 their climatic difference for short and medium distances, but not for long distances.

329 The results were similar when random points were simulated around every host site within 330 a radius equal to 0.25 times the distance separating source and host sites (Fig.6). Thus, in a given 331 area (of $\sim 0.2$ times the square of the distance between the chosen source and host sites), the local 332 positioning of host site tended to minimize the climatic difference with the source site for short and 333 medium distances, but not for long distances.

\section{Discussion}

\section{- Geographic and climate distances and directions}

339 In this paper we have compared the geographical locations and climatic conditions of host and 340 source sites involved in translocations of plant species that aim to achieve viable populations in the 341 Western Palearctic in the last decades. Most plant translocations were conducted at distances of 342 less than $25 \mathrm{~km}$. These distances are small when comparing them with the projected speed of 
343 climate change for the 21 st century expressed in poleward shift per year in, e.g., Mediterranean 344 forests, woodlands and scrub $\left(0.26 \mathrm{~km} \cdot \mathrm{yr}^{-1}\right)$ or temperate broadleaf and mixed forests $\left(0.35 \mathrm{~km} . \mathrm{yr}^{-}\right.$

345 1; Loarie et al., 2009). These short distances can be explained by the fact that it is easier to find 346 similar habitats, likely to be suitable for the species, close to the source sites, but also by 347 administrative and legal reasons, which we discuss below in the subsection about the many 348 dimensions of site selection. In a very recent study, Skikne et al. (2020) estimated longer 349 translocation distances in birds (median=105 km), using data from the Avian Reintroduction and 350 Translocation database (Lincoln Park Zoo, 2012), including many translocations from New 351 Zealand and the USA. Interestingly, they showed that the proportion of surviving birds one year 352 after release decreased with longer distance translocations. As in our study, Skikne et al. observed 353 that geographic and climatic distances between source and host sites were correlated, but not 354 equivalent. But neither geographic nor climatic directions were documented in Skikne et al.'s study, 355 and we are not aware of any such studies in plants.

356 In a context where climate change is an important concern for the conservation of species 357 diversity (Thomas et al., 2004; Thuiller et al., 2005; Bellard et al., 2012; Urban, 2015), one would 358 think that species translocations, whatever their main motivation, would represent an opportunity 359 to move plant material (or the genetic information carried by this material) polewards, or higher in 360 altitude, to cooler climatic conditions (Fahselt, 2007; Brooker et al., 2011; Aitken \& Whitlock, 361 2013). We actually found that the translocations were not made preferentially in the direction of 362 any cardinal point, nor towards a higher altitude. Yet on the climatic compass, the two axes of 363 which are derived from the PCA on the seven bioclimatic variables, the host sites were located on 364 average in significantly cooler climatic positions than the source sites. We did not necessarily 365 expect this result when we read the documents used for our database. While some documents 
suggested that global warming was one of the factors threatening the translocated species, none of 367 them explicitly described the translocation project as a means of mitigating the negative effects of 368 global warming. In addition, $82 \%$ of the source-host distances were less than $25 \mathrm{~km}$, which limited 369 the possibilities for climate differentiation. However, in a number of cases where managers had the 370 choice between different candidate sites for the creation of new populations or reintroductions, they 371 mentioned that they avoided sites where introduced individuals could suffer from excessive heat 372 or drought (e.g., Fraga, 2000; Guyonneau \& Amiotte-Suchet, 2019). This avoidance of sites with 373 a relatively warmer and drier climate than other nearby sites (perhaps because of the slope, sun 374 exposure, soil...) is probably the reason for our results. It is therefore fair to state that past 375 translocations were more often made to sites where the effects of global warming on species could 376 be limited rather than amplified. But in these cases, translocations were not considered in 377 anticipation of future climate change to prevent the degradation of the conservation status of 378 species whose populations could become extinct. It was within the framework of conservation 379 programmes already underway to slow the decline of species that managers chose translocation 380 sites in response to climate change, the effects of which were already tangible.

To go further, and possibly demonstrate that past translocations have helped to mitigate negative impacts of climate change on species conservation, it would be ideal to compare the 383 viability of populations that have been translocated in contrasted climatic directions. Unfortunately, 384 our post-translocation demographic data are currently too sparse and insufficiently standardised to 385 allow such an analysis, even with a viability proxy.

The results of experiments in common gardens have shown an advantage of genotypes from warmer sites over local genotypes in Mimulus guttatus (Peterson et al., 2016) and Clarkia pulchella 388 (Bontrager \& Angert, 2019). Simulation results have shown that assisted gene flow is likely to 
reduce maladaptation caused by climate change, despite outbreeding depression, in many cases

390 (Aitken \& Whitlock, 2013). All these results suggest that translocations can be a useful tool in species management to facilitate the adaptation of species to climate change (Aitken \& Whitlock, 2013; Quigley et al, 2019), although some authors have pointed out that other local adaptation factors, such as soil or biotic interactions, may limit the interest of translocations and assisted gene flow (Bucharova, 2017). The identification of source sites currently experiencing the expected 395 future climatic conditions in host sites is already included in translocation projects for long-lived trees, which may be part of productive forest plantation programmes (O'Neill et al., 2017) or ecological restoration programmes (Booth \& Muir, 2020). It is likely (and hoped) that this approach will be more widely used in the future, notably for translocations of threatened species, although, in these cases, the choice of source and host sites is generally much more restricted than in the case of forest trees.

When we divided our dataset into four quartiles, according to the latitude of the host sites, 402 we observed that compared to the most southern operations, the most northern operations tended 403 to be at longer distances and further to the south (Supporting Information). The longer distances 404 can be explained by the fact that there are fewer micro-endemic species of particular habitats, which 405 tend to be translocated locally, in northern Europe than in the south. As for the more southerly 406 directions, they could be related to the fact that from a certain latitude in northern Europe, human 407 density and the associated frequency of degraded habitats decrease as one moves northwards. 408 Habitat restoration and reintroduction of species may in these circumstances lead managers to bring 409 back plant material from north to south. But these results and interpretations should be considered 410 with great caution, since our dataset contains many more translocation operations carried out in 411 Latin countries than in Northern Europe, where we have only had access to some (probably large) 
412 operations published in English (see subsection about the limits due to translocation practices and 413 data availability).

415 - Extent of climatic differences between source and host sites

416 When translocation distances were less than $50 \mathrm{~km}$, the climatic difference between the

417 source and host sites was smaller than if the host sites had been randomly selected regardless of 418 how the random selection was made, i.e. either at a given distance in any direction around the 419 source site, or in a buffer zone locally centred around the actual host site. It would be tempting to 420 interpret this result as the consequence of a choice aimed at minimising the climatic distance 421 between host and source sites. But it is quite possible that this short climatic distance is only a 422 secondary effect of the choice of a favourable habitat for the translocated species on other criteria. 423 For example, when a plant living on coastal sand dunes is translocated, it is translocated to other 424 coastal habitats, where sand dunes can be found, thus excluding inland, possibly mountainous, 425 areas nearby. For a given geographical distance between them, two coastal sites are generally 426 climatically closer to each other than a coastal site with a mountainous site, and therefore choosing 427 a habitat favourable to the translocated plant on criteria other than the climatic criterion (such as 428 soil texture or plant cover) may correlatively minimise the climatic distance without it having been 429 included in the selection of the location of the sites.

430 Beyond $50 \mathrm{~km}$, on the other hand, the climatic difference between the source sites and the 431 actually selected host sites was no smaller than if the host sites had been selected at random, using 432 both random selection methods. This result is intriguing, as the choice of habitat remains paramount 433 over long distances. It could be related to the fact that microendemic species in Mediterranean 434 coastal areas, including islands, have not been subject to long-distance translocations (see Figure 
435 1). In regions where such translocations have taken place (Great Britain, northern France, Sweden,

436 Eastern Europe), the landscapes are less heterogeneous and the climatic gradients are probably

437 smoother, which may account for climatic distances that are not very different when host sites are

438 randomly drawn in a buffer zone around the actual host site. However, this explanation is

439 unconvincing when host sites are randomly drawn in any direction around the source site, where

440 the actual host sites may be far away from the random host sites (see Supporting Information Figure

441 S2, Simulation 1). On the whole, the simulation results finally seem rather inconclusive, and do

442 not allow us to affirm that the practitioners have endeavoured to minimise the climatic difference

443 between the source and host sites.

\section{- Limits due to translocation practices and data availability-}

We analysed a sample of translocations in Europe over the last 50 years. This sample is not random, and it might be biased in several ways. Firstly, the documents we relied on (peer-reviewed

448 scientific articles, books, theses, conference papers, presentations, reports, newspaper articles, webpages, etc.) were mostly written in French, Spanish, Italian, and English, which excluded from

450 our sample translocations for which the information we were looking for was only written in other

451 languages. Secondly, many translocations are unknown to us. A number of them were carried out

452 on individual initiatives by botanists, especially before the establishment of legal frameworks for

453 these operations in Europe with the rise of the Natura2000 network. These attempts have generally

454 been kept secret, whether or not they have resulted in persistent populations. Other translocations

455 were carried out before the 2000s in a regulated and legal manner by nature management

456 organisations, but their memory has more or less been lost because the reports concerning them

457 have never been digitised or centralized. Thirdly, some translocations are known but we did not 
458 find sufficiently precise geographical information. This was either because people did not consider 459 accurate location information (especially of source populations) to be very important, or to keep 460 confidential the location of emblematic species to avoid too much frequentation or collection (for 461 example the populations of Cypripedium calceolus in England or Switzerland, Joint Nature 462 Conservation Committee, 2007; Parc Régional Chasseral, 2011).

Another limitation is that not all of our geographic data was very accurate. When they were not, the central coordinates of the territories we used (e.g. municipal territory, island, buffer around a village) did not necessarily correspond to the exact location of the population and might have 466 distorted the geographical distances and directions calculated between source and host sites. 467 Similarly, imprecise geographic coordinates may have corresponded to climate pixels in the 468 WorldClim database that were different from the actual climate pixels of the source and host sites. 469 But there is no reason to believe that these inaccuracies biased our results in one direction or 470 another. Finally, because there are no weather stations in every $\mathrm{km}^{2}$ in Europe, the values provided 471 for many climate pixels by the WorldClim database might be smoothed in gradients between 472 weather stations, thus erasing local variations due for example to sunlight on slopes (see Scherrer 473 et al., 2011, about the discrepancy between weather station data and temperature variation due to 474 topography). But this phenomenon is probably limited by the fact WorldClim data were obtain

475 from models using not only weather station data but also covariates such as elevation, distance to 476 the coast and satellite-derived data (land surface temperature and cloud cover, Fick \& Hijmans 477 2017). 

on the objectives of the translocation. Even if the translocations included in our database were all 482 aimed at leading to a viable population, they sometimes contain other objectives such as 483 experimentation (e.g., Sainz-Ollero \& Hernández-Bermejo, 1979; Colas et al., 2008; Dalrymple \& 484 Broome, 2010), ecological restoration (Kiehl \& Pfadenhauer, 2007), or ecosystem service supply 485 (Arnold et al., 2005; Walter, 2005). In addition, the way in which sites are selected varies. 486 Sometimes the source site is determined in advance because it is itself at the origin of the 487 translocation project. This is the case when a natural area containing protected species is degraded 488 for the needs of a human activity and a host site is sought for the implantation of these species so 489 that their conservation status is not unduly altered (e.g., Cochlearia polonica, Cieślak et al., 2010). 490 Sometimes, the project comes directly from a desire to reintroduce a taxon to a site from which it 491 has disappeared or to reinforce an existing population. In such cases, one or more sites of origin 492 are searched for and selected (Adamec \& Lev, 1999). In other cases, finally, the project, focusing 493 on a taxon whose populations are to be increased, offers the possibility of selecting both one or 494 more source site(s) and one or more host site(s) from a range of possibilities (Guyonneau \& 495 Amiotte-Suchet, 2019).

The selection of source and host sites depends of course on ecological considerations: 497 population size, similarity of habitat, geographical and climatic distances, etc. However, many 498 other aspects, including socio-economic and legal ones, probably guide this selection but were not 499 considered in our analysis. Access to land depends on its ownership and relies on the owner's 500 willingness to sell the land or sign a contract to host the taxon. Other aspects might include its 501 status as protected or not, the probable evolution of its use, and other administrative or legal 502 constraints. Some countries might favor short distance translocation in the implementation of some 
503 specific public policies, which might partly explain why a significant number of translocations are 504 implemented at short geographic distance from the source site. This is the case for France and 505 Spain, which have small translocation distances compared to the whole dataset (Supporting 506 information Table S2). For example in France, in the context of the mitigation hierarchy (i.e., 507 avoiding, reducing and, as a last resort, offsetting for damages to biodiversity) that developers are 508 supposed to follow when proposing a new project, translocations were considered as offsetting 509 measures until recently and were thus supposed to follow the corresponding guidelines requiring 510 to keep the measures at a functional proximity from the impacted area (MEDTL, 2012, now Art. 511 L. 163-1 II of the French environmental code). In Spain, another country that provided many entries 512 in the database, the competence on environmental matters have been transferred to sub-national 513 structures (Autonomous Communities in Spain). This organisation forces de facto translocations 514 to take place preferentially within the territories governed by sub-national structures. It is still 515 possible to undertake translocations that involve two sub-national territories, but it is obviously a 516 lot more difficult as they have to be approved and coordinated by the authorities of both entities 517 (see the unpublished Spanish guide for translocations approved by the Comisión Estatal para el 518 Patrimonio Natural y la Biodiversidad in 2013, available at 519 https://www.miteco.gob.es/es/biodiversidad/temas/conservacion-de520 especies/doc_directrices_reintroduccion_tcm30-198128.pdf).

521 The reduction of site availability due to these non-ecological dimensions might lead to a 522 situation where the remaining sites do not allow stakeholders to consider climate change 523 predictions (Fahselt, 2007). Further research based on enquiries among translocation practitioners 524 should deserve considerations to identify the overriding factors for the selection of sites that might 525 explain part of our observations. 
527 - Conclusion-

528 Past translocations have, for the most part, been conducted by skilled practitioners who were 529 committed to finding the most favourable ecological conditions possible to achieve viable 530 populations. Climate change is a factor that must be taken into account in the choice of sites, among 531 other important factors such as soil texture, $\mathrm{pH}$ and moisture, competition with other plant species, 532 predation, human frequentation, land ownership, management method, administrative, legal and 533 economic constraints, etc. The considerations are therefore often very complex. Although past 534 translocations have been to slightly cooler sites, climate change does not appear to have been a 535 major consideration. We are now in a time of rapid anthropogenic climate change, and it is likely 536 that this factor will need to be taken into account to a much greater extent over the next few decades 537 if translocations are to improve the viability of plant populations that generally have limited 538 dispersal ability.

\section{Acknowledgements}

541 This study was financially supported by the Initiative de Recherche Stratégique ACE-ICSEN from

542 Université Paris-Saclay, by the "Partenariats" projects from LabEx BASC, and by a PEPS project 543 from CNRS-INEE. The authors would like to thank the many people who contributed to the data 544 collection. 


\section{Author's contributions}

$548 \mathrm{MD}, \mathrm{SO}, \mathrm{JFM}, \mathrm{ACV}$ and BC conceived the ideas and designed methodology; MD, AM, AGF, JMI

549 and $\mathrm{BC}$ collected the data; $\mathrm{SO}, \mathrm{MD}$, and JFM analysed the data; $\mathrm{BC}$ led the writing of the 550 manuscript. All authors contributed critically to the drafts and gave final approval for publication.

552 Data availability

553 The data used in this paper are locations of plant species, many of which are endangered. Some 554 precise locations are publicly available in scientific articles or non-confidential reports. Others 555 were given to us by providing confidential reports or during interviews, and we have no right to 556 make them public. Degraded data (e.g. to the municipality level) of all locations are accessible 557 through the TransLoc website (http://translocations.in2p3.fr/index.php). R-scripts used for data 558 analyses are available in Supporting information. 
561

562

563

564

565

566

567

568

569

570

571

572

573

574

575

576

577

578

579

580

581

\section{References}

Adamec, L., \& Lev, J. (1999). The Introduction of the Aquatic Carnivorous Plant Aldrovanda vesiculosa to New Potential Sites in the Czech Republic: A Five-Year Investigation. Folia Geobotanica, 34, 299-305. https://doi.org/10.1007/BF02912816

Aitken, S. N., \& Whitlock, M. C. (2013). Assisted Gene Flow to Facilitate Local Adaptation to Climate Change. Annual Review of Ecology, Evolution, and Systematics, 44, 367-388. https://doi.org/10.1146/annurev-ecolsys-110512-135747

Arnold, C., Schnitzler, A., Douard, A., Peter, R., \& Gillet, F. (2005). Is there a future for wild grapevine (Vitis vinifera subsp. silvestris) in the Rhine Valley? Biodiversity and Conservation, 14, 1507-1523. https://doi.org/10.1007/s10531-004-9789-9

Bellard, C., Bertelsmeier, C., Leadley, P., Thuillier, W., \& Courchamp, F. (2012). Impacts of climate change on the future of biodiversity. Ecology Letters, 15, 365-377. https://doi.org/10.1111/j.1461-0248.2011.01736

Biere, A., van Andel, J., \& van de Koppel, J. (2012). Populations: Ecology and Genetics. In J. van Andel \& J. Aronson (Eds.), Restoration Ecology: The New Frontier (pp. 73-86). John Wiley \& Sons, Ltd. https://doi.org/10.1002/9781118223130.ch7

Bontrager, M., \& Angert, A. L. (2019). Gene flow improves fitness at a range edge under climate change. Evolution Letters, 3(1), 55-68. https://doi.org/10.1002/evl3.91

Booth, T. H., Nix, H. A., Busby, J. R., \& Hutchinson, M. F. (2014). BIOCLIM: The first species distribution modelling package, its early applications and relevance to most current Maxent studies. Diversity and Distributions, 20, 1-9. https://doi.org/10.1111/ddi.12144 
Brook, B., Sodhi, N., \& Bradshaw, C. (2008). Synergies among extinction drivers under global 583 change. Trends in Ecology \& Evolution, 23, 453-460. https://doi.org/10.1016/j.tree.2008.03.011

584 Brooker, R., Britton, A., Gimona, A., Lennon, J., \& Littlewood, N. (2011). Literature review: 585 Species translocations as a tool for biodiversity conservation during climate change. Scottish 586 Natural Heritage Commissioned Report No.440.

587 Bucharova, A. (2017). Assisted migration within species range ignores biotic interactions and lacks 588 evidence. Restoration Ecology, 25, 14-18. https://doi.org/10.1111/rec.12457

589 Cieślak, E., Kaźmierczakowa, R., \& Ronikier, M. (2010). Cochlearia polonica Fröhl. 590 (Brassicaceae), a narrow endemic species of southern Poland: History of conservation efforts, 591 overview of current population resources and genetic structure of populations. Acta Societatis 592 Botanicorum Poloniae, 79, 255-261.

593 Colas, B., Kirchner, F., Riba, M., Olivieri, I., Mignot, A., Imbert, E., ... Fréville, H. (2008). 594 Restoration demography: A 10-year demographic comparison between introduced and natural 595 populations of endemic Centaurea corymbosa (Asteraceae). Journal of Applied Ecology, 45, 596 1468-1476. https://doi.org/10.1111/j.1365-2664.2008.01536.x

597 Colas, B., Olivieri, I., \& Riba, M. (1997). Centaurea corymbosa, a cliff-dwelling species tottering 598 on the brink of extinction: A demographic and genetic study. Proceedings of the National Academy 599 of Sciences, 94, 3471-3476. https://doi.org/10.1073/pnas.94.7.3471

600 Colas, B., Thomas, C. D., \& Hanski, I. (2004). Adaptive responses to landscape disturbances: 601 Empirical evidence. In R. Ferrière, U. Dieckman, \& D. Couvet (Eds.), Evolutionary Conservation 602 Biology (pp. 284-299). Cambridge University 603 https://doi.org/10.1017/CBO9780511542022.020 
604 Dalrymple, Sarah E., \& Broome, A. (2010). The importance of donor population identity and 605 habitat type when creating new populations of small cow-wheat Melampyrum sylvaticum from seed 606 in Perthshire, Scotland. Conservation $\quad$ Evidence, $\quad$ 1-8, 607 https://doi.org/10.6084/M9.FIGSHARE.649427

608 Dalrymple, S.E., Stewart, G. B., \& Pullin, A. S. (2011). Are re-introductions an effective way of 609 mitigating against plant extinctions? CEE review 07-008 (SR32). Collaboration for Environmental 610 Evidence: www.environmentalevidence.org/

611 Dullinger, S., Dendoncker, N., Gattringer, A., Leitner, M., Mang, T., Moser, D., ... Hülber, K. 612 (2015). Modelling the effect of habitat fragmentation on climate-driven migration of European 613 forest understorey plants. Diversity and Distributions, 21, 1375-1387. 614 https://doi.org/10.1111/ddi.12370

615 European Environment Agency. (2011). Landscape fragmentation in Europe. Joint EEA-FOEN 616 report No 2/2011. European Environment Agency.

617 Fagan, W. F., \& Holmes, E. E. (2005). Quantifying the extinction vortex. Ecology Letters, 9, 51618 60. https://doi.org/10.1111/j.1461-0248.2005.00845.x

619 Fahrig, L. (2017). Ecological Responses to Habitat Fragmentation Per Se. Annual Review of 620 Ecology, Evolution, and Systematics, 48, 1-23. https://doi.org/10.1146/annurev-ecolsys-110316621022612

622 Fahselt, D. (2007). Is transplanting an effective means of preserving vegetation? Canadian Journal 623 of Botany, 85, 1007-1017. https://doi.org/10.1139/B07-087 
624 Fick, S. E., \& Hijmans, R. J. (2017). WorldClim 2 : New 1-km spatial resolution climate surfaces 625 for global land areas. International Journal of Climatology, 37, 4302-4315. 626 https://doi.org/10.1002/joc.5086

627 Fletcher, R. J., Didham, R. K., Banks-Leite, C., Barlow, J., Ewers, R. M., Rosindell, J., ... Haddad, 628 N. M. (2018). Is habitat fragmentation good for biodiversity? Biological Conservation, 226, 9-15. 629 https://doi.org/10.1016/j.biocon.2018.07.022

630 Fraga, P. (2000). Intentos de reintroducción de Lysimachia minoricensis J.J. Rodr. En Menorca. 631 Conservacion Vegetal, 5, 12.

632 Frankham, R. (2005). Genetics and extinction. Biological Conservation, 126, 131-140. 633 https://doi.org/10.1016/j.biocon.2005.05.002

634 Futuyma, D. J. (1986). Evolutionary Biology (2nd ed.). Sunderland, Mass: Sinauer Associates, Inc. 635 https://doi.org/10.1046/j.1420-9101.1988.1010089.x

636 GADM. (2018). Database of Global Administrative Areas (3.6) [Computer software]. 637 https://gadm.org/data.html

638 Godefroid, S., Piazza, C., Rossi, G., Buord, S., Stevens, A.-D., Aguraiuja, R., ... Vanderborght, T. 639 (2011). How successful are plant species reintroductions? Biological Conservation, 144, 672-682. 640 https://doi.org/10.1016/j.biocon.2010.10.003

641 Google Inc. (2017). Google Earth. Google Inc. https://www.google.com/earth/

642 Guyonneau, J., \& Amiotte-Sucher, J. (2019). Le retour de la Saxifrage oeil-de-bouc. Espaces 643 Naturels, 65, 53-54. 
644 Hanski, I., Zurita, G. A., Bellocq, M. I., \& Rybicki, J. (2013). Species-fragmented area relationship.

645 Proceedings of the National Academy of Sciences, 110, 12715-12720.

646 https://doi.org/10.1073/pnas.1311491110

647 Haskins, K. E. (2015). Alternative perspectives on reintroduction success. Animal Conservation, 648 18, 409-410. https://doi.org/10.1111/acv.12241

649 Hufbauer, R. A., Szücs, M., Kasyon, E., Youngberg, C., Koontz, M. J., Richards, C., Tuff, T., \&

650 Melbourne, B. A. (2015). Three types of rescue can avert extinction in a changing environment.

651 Proceedings of the National Academy of Sciences, 112, 10557-10562.

652 https://doi.org/10.1073/pnas.1504732112

653 Joint Nature Conservation Committee. (2007). Second Report by the UK under Article 17 on the

654 implementation of the Habitats Directive from January 2001 to December 2006. Peterborough:

655 JNCC. Available from: www.jncc.gov.uk/article17

656 Kiehl, K., \& Pfadenhauer, J. (2007). Establishment and persistence of target species in newly 657 created calcareous grasslands on former arable fields. Plant Ecology, 189, 31-48. 658 https://doi.org/10.1007/s11258-006-9164-X

659 Lacy, R. C. (2000). Considering Threats to the Viability of Small Populations Using Individual660 Based Models. Ecological Bulletins, 48, 39-51. https://doi.org/10.2307/20113247

661 Laguna, E., Navarro, A., Pérez-Rovira, P., Ferrando, I., \& Ferrer-Gallego, P. P. (2016). 662 Translocation of Limonium perplexum (Plumbaginaceae), a threatened coastal endemic. Plant 663 Ecology, 217, 1183-1194. https://doi.org/10.1007/s11258-016-0643-4

664 Lavergne, S., Mouquet, N., Thuiller, W., \& Ronce, O. (2010). Biodiversity and Climate Change: 665 Integrating Evolutionary and Ecological Responses of Species and Communities. Annual Review 
666 of Ecology, Evolution, and Systematics, 41, 321-350. https://doi.org/10.1146/annurev-ecolsys$667 \quad 102209-144628$

668 Lenoir, J., Gegout, J. C., Marquet, P. A., de Ruffray, P., \& Brisse, H. (2008). A Significant Upward 669 Shift in Plant Species Optimum Elevation During the 20th Century. Science, 320, 1768-1771. 670 https://doi.org/10.1126/science.1156831

671 Loarie, S. R., Duffy, P. B., Hamilton, H., Asner, G. P., Field, C. B., \& Ackerly, D. D. (2009). The 672 velocity of climate change. Nature, 462(7276), 1052-1055. https://doi.org/10.1038/nature08649

673 MEDDTL - Ministère de 1'Ecologie, du Développement Durable, des Transports et du Logement. 674 (2012). Doctrine relative à la séquence éviter, réduire et compenser-Les impacts sur le milieu 675 naturel.

676 Menges, E. S. (2008). Restoration demography and genetics of plants: When is a translocation 677 successful? Australian Journal of Botany, 56, 187. https://doi.org/10.1071/BT07173

678 Nix, H. A. (1986). A biogeographic analysis of Australian elapid snakes. In R. Longmore (Ed.), 679 Atlas of elapid snakes of Australia: Australian Flora and Fauna series 7 (pp. 4-15). Australian 680 Government Publishing Service.

681 Noël, F., Prati, D., van Kleunen, M., Gygax, A., Moser, D., \& Fischer, M. (2011). Establishment 682 success of 25 rare wetland species introduced into restored habitats is best predicted by ecological 683 distance to source habitats. Biological Conservation, 144, 602-609. 684 https://doi.org/10.1016/j.biocon.2010.11.001

685 O’Donnell, M. S., \& Ignizio, D. A. (2012). Bioclimatic predictors for supporting ecological 686 applications in the conterminous United States. U.S. Geological Survey Data Series 691.

687 Parc Régional Chasseral. (2011). Rapport d'activités 2011. 
O’Neill, G., Wang, T., Ukrainetz, N., Charleson, L., McAuley, L., Yanchuk, A., \& Zedel, S. (2017).

689 A proposed climate-based seed transfer system for British Columbia. Prov. B.C., Victoria, B.C. 690 Tech. Rep. 099. www.for.gov.bc.ca/hfd/pubs/Docs/Tr/Tr099.htm

691 Peterson, M. L., Kay, K. M., \& Angert, A. L. (2016). The scale of local adaptation in Mimulus 692 guttatus : Comparing life history races, ecotypes, and populations. New Phytologist, 211, 345-356. 693 https://doi.org/10.1111/nph.13971

694 Quigley, K. M., Bay, L. K., \& Oppen, M. J. H. (2019). The active spread of adaptive variation for 695 reef resilience. Ecology and Evolution, 9(19), 11122-11135. https://doi.org/10.1002/ece3.5616

696 R Core Team. (2019). R: A language and environmentfor statistical computing. R Foundation for 697 Statistical Computing. https://www.R-project.org/

698 Riba, M., Mignot, A., Fréville, H., Colas, B., Imbert, E., Vile, ... Olivieri, I. (2005). Variation in 699 Dispersal Traits in a Narrow-endemic Plant Species, Centaurea corymbosa Pourret. (Asteraceae). 700 Evolutionary Ecology, 19(3), 241-254. https://doi.org/10.1007/s10682-005-0913-4

701 Robert, A., Colas, B., Guignon, I., Kerbiriou, C., Mihoub, J.-B., Saint-Jalme, M., \& Sarrazin, F. 702 (2015a). Defining reintroduction success using IUCN criteria for threatened species: A 703 demographic assessment. Animal Conservation, 18, 397-406. https://doi.org/10.1111/acv.12188

704 Robert, A., Colas, B., Guignon, I., Kerbiriou, C., Mihoub, J.-B., Saint-Jalme, M., \& Sarrazin, F. 705 (2015b). Reintroducing reintroductions into the conservation arena. Animal Conservation, 18, 706 413-414. https://doi.org/10.1111/acv.12244

707 Román-Palacios, C., \& Wiens, J. J. (2020). Recent responses to climate change reveal the drivers 708 of species extinction and survival. Proceedings of the National Academy of Sciences, 117, 709 4211-4217. https://doi.org//10.1073/pnas.1913007117 
Sainz-Ollero, H., \& Hernández-Bermejo, J. E. (1979). Experimental reintroductions of endangered

711 plant species in their natural habitats in Spain. Biological Conservation, 16, 195-206. 712 https://doi.org/10.1016/0006-3207(79)90021-1

713 Scherrer, D., Schmid, S., \& Körner, C. (2011). Elevational species shifts in a warmer climate are 714 overestimated when based on weather station data. International Journal of Biometeorology, 55(4), 715 645-654. https://doi.org/10.1007/s00484-010-0364-7

716 Seddon, P. J. (2015). Using the IUCN Red List criteria to assess reintroduction success. Animal 717 Conservation, 18(5), 407-408. https://doi.org/10.1111/acv.12239

718 Shier, D. M. (2015). Developing a standard for evaluating reintroduction success using IUCN Red 719 List indices. Animal Conservation, 18(5), 411-412. https://doi.org/10.1111/acv.12242

720 Silcock, J. L., Simmons, C. L., Monks, L., Dillon, R., Reiter, N., Jusaitis, M., Vesk, P. A., Byrne, 721 M., \& Coates, D. J. (2019). Threatened plant translocation in Australia: A review. Biological 722 Conservation, 236, 211-222. https://doi.org/10.1016/j.biocon.2019.05.002

723 Skikne, S. A., Borker, A. L., Terrill, R. S., \& Zavaleta, E. (2020). Predictors of past avian 724 translocation outcomes inform feasibility of future efforts under climate change. Biological 725 Conservation, 247, 108597. https://doi.org/10.1016/j.biocon.2020.108597

726 Soorae, P. S. (Éd.). (2018). Global reintroduction perspectives: 2018. Case studies from around the 727 globe (6 éd.). IUCN/SSC Reintroduction Specialist Group, Gland, Switzerland and Environment 728 Agency, Abu Dhabi, UAE. https://doi.org/10.2305/IUCN.CH.2018.08.en

729 Thomas, C. D., Cameron, A., Green, R. E., Bakkenes, M., Beaumont, L. J., Collingham, Y. C., 730 Erasmus, B. F. N., de Siqueira, M. F., Grainger, A., Hannah, L., Hughes, L., Huntley, B., van 731 Jaarsveld, A. S., Midgley, G. F., Miles, L., Ortega-Huerta, M. A., Peterson, A. T., Phillips, O. L., 
$732 \&$ Williams, S. E. (2004). Extinction risk from climate change. 427, 145-148. https://doi.org/ $733 \quad 10.1038 /$ nature02121

734 Thuiller, W., Lavorel, S., Araujo, M. B., Sykes, M. T., \& Prentice, I. C. (2005). Climate change 735 threats to plant diversity in Europe. Proceedings of the National Academy of Sciences, 102(23), 736 8245-8250. https://doi.org/10.1073/pnas.0409902102

737 Urban, M. C. (2015). Accelerating extinction risk from climate change. Science, 348(6234), 738 571-573. https://doi.org/10.1126/science.aaa4984

739 Vilà, C., Sundqvist, A., Flagstad, Ø., Seddon, J., Bjö rnerfeldt, S., Kojola, I., ... Ellegren, H. (2003). 740 Rescue of a severely bottlenecked wolf (Canis lupus) population by a single immigrant. 741 Proceedings of the Royal Society of London. Series B: Biological Sciences, 270, 91-97. 742 https://doi.org/10.1098/rspb.2002.2184

743 Walter, M. (2005). Transplanting and sowing seed of common cow-wheat Melampyrum pratense 744 to increase its distribution at Blean Woods RSPB Reserve, Kent, England. Conservation Evidence, 745 2, 41-42. https://www.conservationevidence.com/individual-study/2150 


\section{Table}

748 Table 1. Bootstrap confidence intervals for the differences in geographic and climatic variables

749 between host and source sites for plant translocations in the Western Palearctic (host site values

750 minus source site values). Latitudes and longitudes are in decimal degrees, and altitudes in meters.

751 Latitudes and longitudes on geographic compass are the coordinates on the geographical axes after

752 transformation of the Euclidean distance between sites. Factorial axes derive from a principal

753 component analysis (PCA) on all climatic data of host and source sites.

754

\begin{tabular}{|c|c|c|}
\hline Variable & lower & upper \\
\hline Latitude & -0.1097 & 0.0222 \\
\hline Latitude (on geographic compass) & -0.0438 & 0.1373 \\
\hline Longitude & -0.2811 & 0.0128 \\
\hline Longitude (on geographic compass) & -0.1420 & 0.0531 \\
\hline Altitude & -20.07 & 53.43 \\
\hline $\begin{array}{l}\text { Coordinates on climatic compass, axis } 1 \\
\text { (cold / hot })\end{array}$ & -0.1377 & -0.0080 \\
\hline $\begin{array}{l}\text { Coordinates on climatic compass, axis } 2 \\
\text { (oceanic / continental gradient) }\end{array}$ & -0.0390 & 0.0692 \\
\hline
\end{tabular}




\section{Figure captions}

758 Figure 1. Location of host sites for plant translocations in the Western Palearctic. The size of the

759 dots depends on the number of populations translocated in the site. The green dots correspond to 760 translocations at a distance $<1 \mathrm{~km}$, the purple ones at distances between 1 and $25 \mathrm{~km}$, the blue ones 761 at distances $>25 \mathrm{~km}$. The blue lines connect the host sites to their source sites for longer distance 762 translocations. The red line and dot symbolize a hypothetical translocation from Paris to London.

764 Figure 2. Location of host sites for plant translocations in the Western Palearctic on a geographic 765 compass (with longitude and latitude axes) where all source sites have been grouped together at a 766 single central point. The size of the dots depends on the number of populations with an identical 767 origin translocated in the host site. The numbers on the dashed circles are the distances in $\mathrm{km}$ 768 between source and host sites (proportional in the figure to the transformed geographical distance, 769 see text). The green dots correspond to translocations at a distance $<1 \mathrm{~km}$, the purple ones at 770 distances between 1 and $25 \mathrm{~km}$, the blue ones at distances $>25 \mathrm{~km}$. The red line and circle 771 symbolize a hypothetical translocation from Paris to London.

773 Figure 3. Relationship between the Euclidian climatic and geographic distances separating source

774 and host sites in Western Palearctic plant translocations. The green dots correspond to 775 translocations at a distance $<1 \mathrm{~km}$, the purple ones at distances between 1 and $25 \mathrm{~km}$, the blue ones 776 at distances $>25 \mathrm{~km}$. The scatterplot is displayed with its two marginal histograms and kernel 777 density estimations. 
779 Figure 4. Principal component analysis of bioclimatic variables in the Western Palearctic. Left:

780 Factorial climate space in the two main components (axes 1 and 2) and vectors corresponding to

781 the seven bioclimatic variables. The mini maps show the geographical variation of the climatic

782 coordinates on axis 1 , which represents a temperature and humidity gradient, and on axis 2 , which

783 represents an oceanic/continental gradient. Right: Location of host sites in the factorial climatic

784 space, with symbolism is as in Fig. 1.

786 Figure 5. Position of host sites for plant translocations in the Western Palearctic on a climatic 787 compass where all source sites have been grouped together at a single central point. The numbers 788 on the dashed circles are the transformed climatic distances. The two axes are the principal axes of 789 a principal component analysis performed on all data in seven bioclimatic variables in the Western 790 Palearctic. The green circles correspond to translocations at a distance $<1 \mathrm{~km}$, the purple ones at 791 distances between 1 and $25 \mathrm{~km}$, the blue ones at distances > $25 \mathrm{~km}$. The red line and circle 792 symbolize a hypothetical translocation from Paris to London.

794 Figure 6. Boxplots showing the distributions of the percentages of simulated geographic points that 795 have an Euclidian climatic distance to the source site lower than that of the true host site. Left: with 796 random simulated points around the source site, at a distance equal to that where the host site is \pm $7975 \%$, in any direction. Right: with random simulated points around the chosen host site, in an area 798 with a radius equal to 0.25 times the distance separating source and host sites. The X-axis separates 799 source-host pairs according the distance between them (in $\mathrm{km}$ ). *** indicates that the proportion 
800 of simulated geographic points with a lower climatic distance from the source site than the true 801 host site was significantly less than $50 \%(P<0.001$, Student's t-tests $)$ 


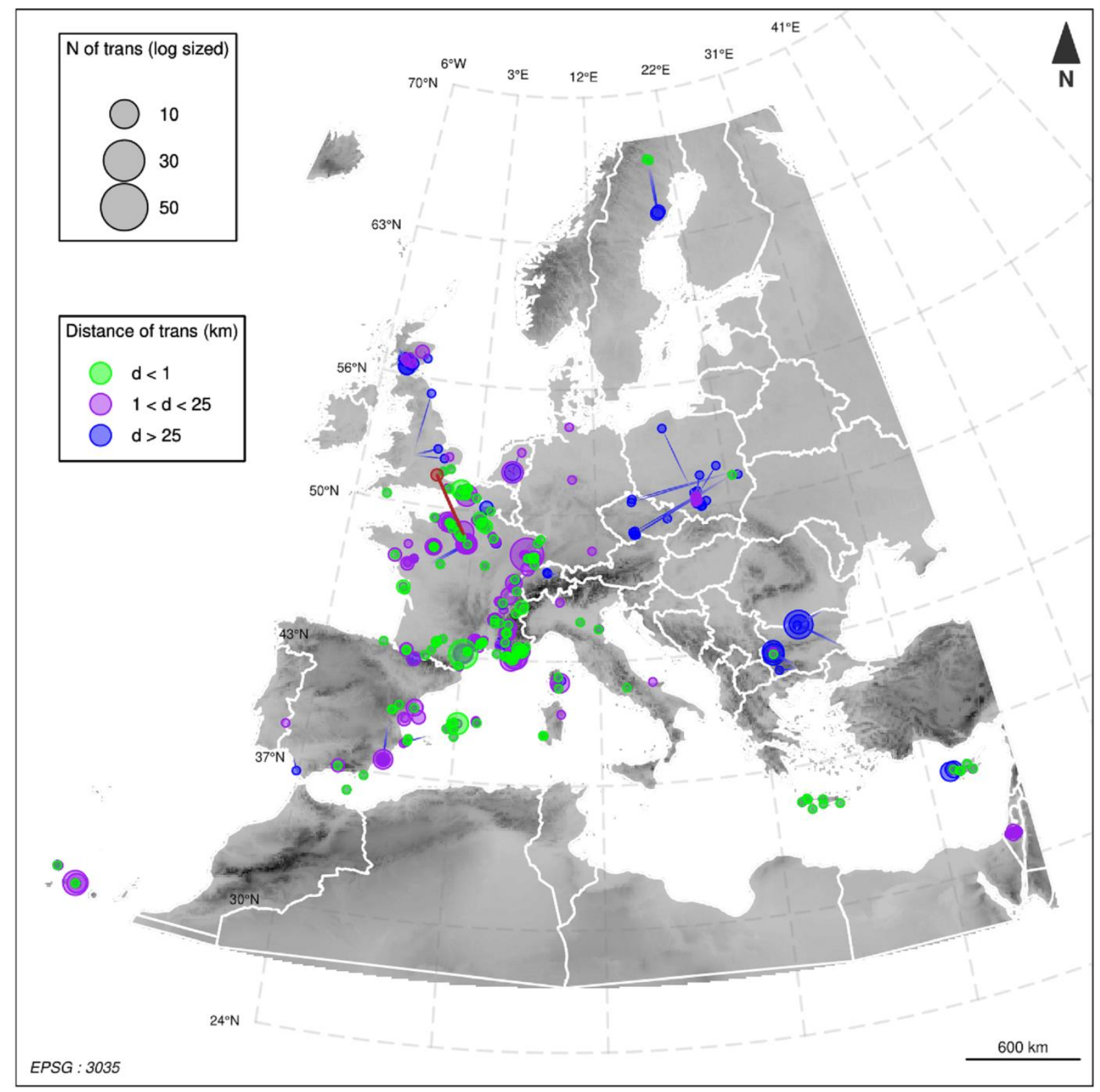

Figure 1. Location of host sites for plant translocations in the Western Palearctic. The size of the dots depends on the number of populations translocated in the site. The green dots correspond to translocations at a distance $<1 \mathrm{~km}$, the purple ones at distances between 1 and $25 \mathrm{~km}$, the blue ones at distances $>25 \mathrm{~km}$. The blue lines connect the host sites to their source sites for longer distance translocations. The red line and dot symbolize a hypothetical translocation from Paris to London. 


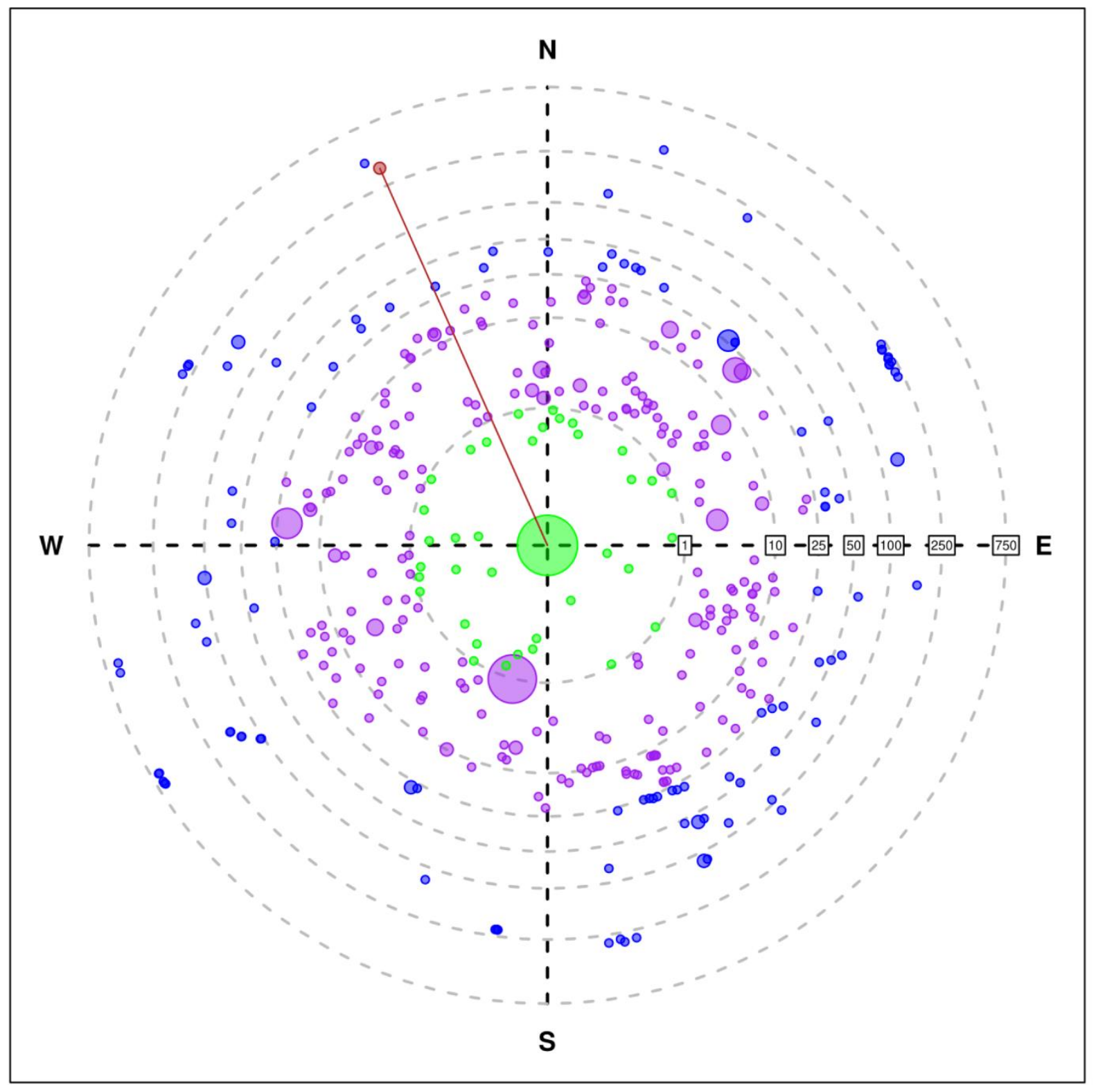

Figure 2. Location of host sites for plant translocations in the Western Palearctic on a geographic compass (with longitude and latitude axes) where all source sites have been grouped together at a single central point. The size of the dots depends on the number of populations with an identical origin translocated in the host site. The numbers on the dashed circles are the distances in $\mathrm{km}$ between source and host sites (proportional in the figure to the transformed geographical distance, see 
text). The green dots correspond to translocations at a distance $<1 \mathrm{~km}$, the purple ones at distances between 1 and $25 \mathrm{~km}$, the blue ones at distances $>25 \mathrm{~km}$. The red line and circle symbolize a hypothetical translocation from Paris to London.

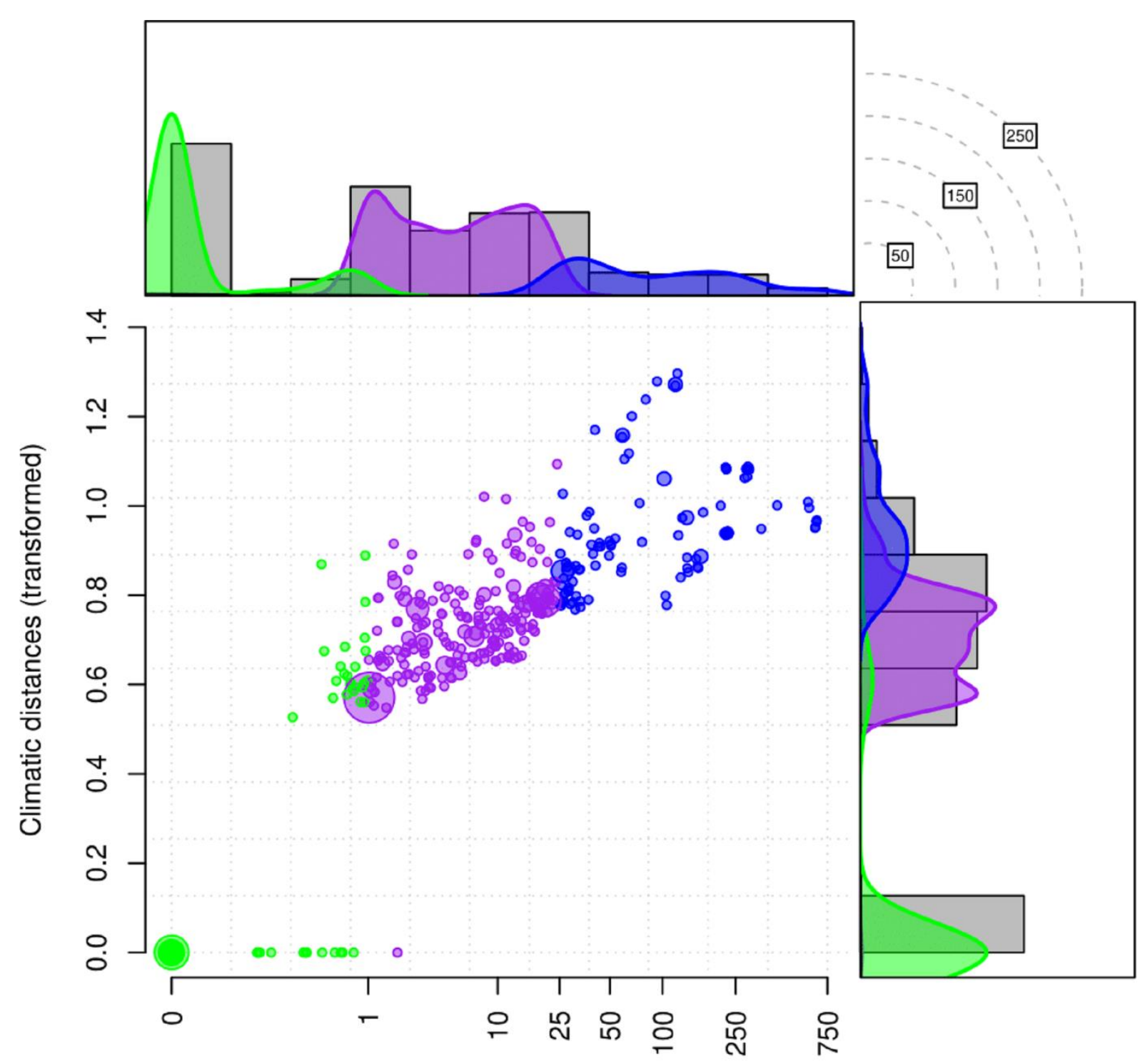

Geographic distances (log transformed, km)

Figure 3. Relationship between the Euclidian climatic and geographic distances separating source and host sites in Western Palearctic plant translocations. The 
green dots correspond to translocations at a distance $<1 \mathrm{~km}$, the purple ones at distances between 1 and $25 \mathrm{~km}$, the blue ones at distances $>25 \mathrm{~km}$. The scatterplot is displayed with its two marginal histograms and kernel density estimations.

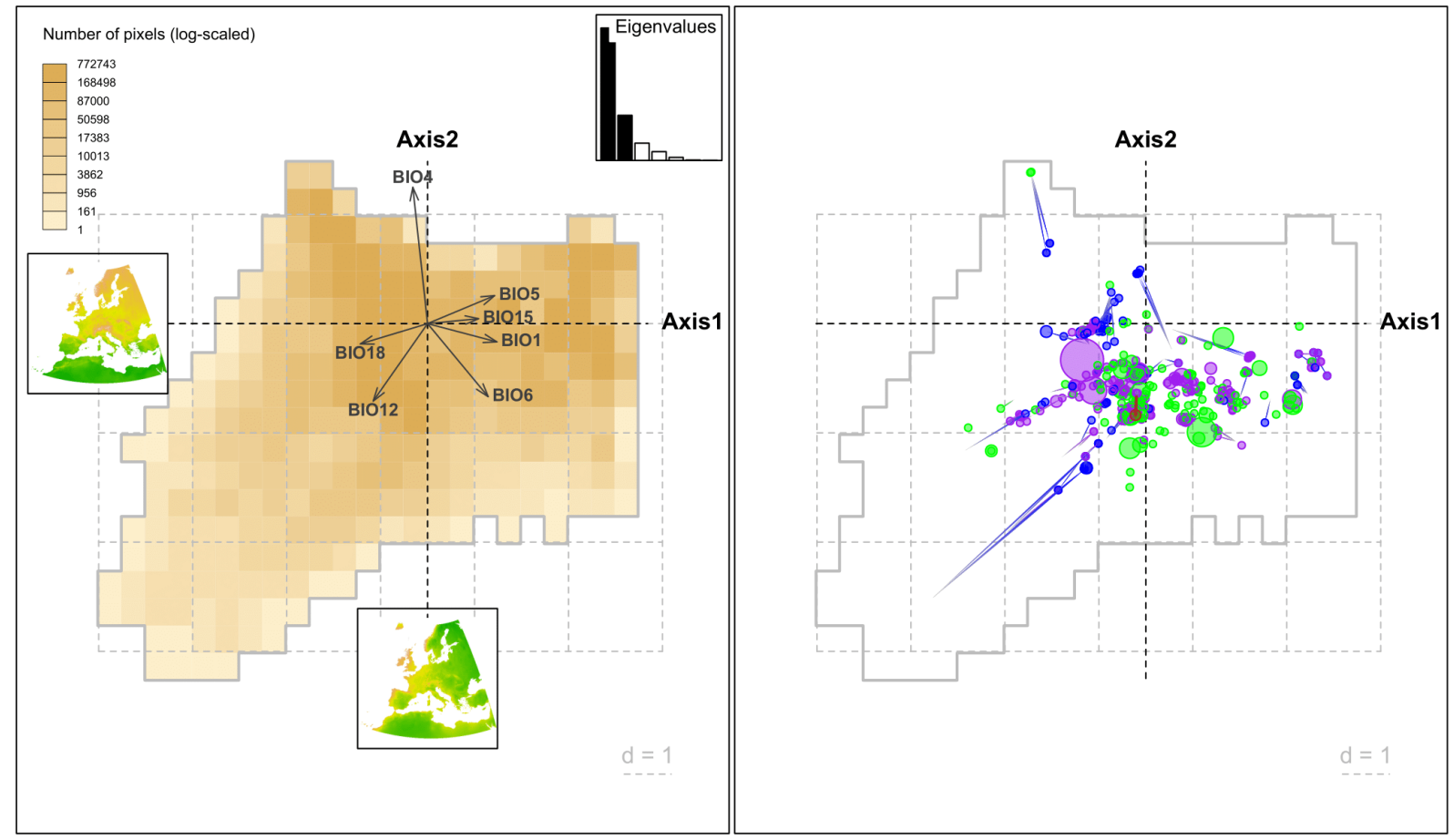

Figure 4. Principal component analysis of bioclimatic variables in the Western Palearctic. Left: Factorial climate space in the two main components (axes 1 and 2) and vectors corresponding to the seven bioclimatic variables. The mini maps show the geographical variation of the climatic coordinates on axis 1 , which represents a temperature and humidity gradient, and on axis 2 , which represents an oceanic/continental gradient. Right: Location of host sites in the factorial climatic space, with symbolism is as in Fig. 1. 


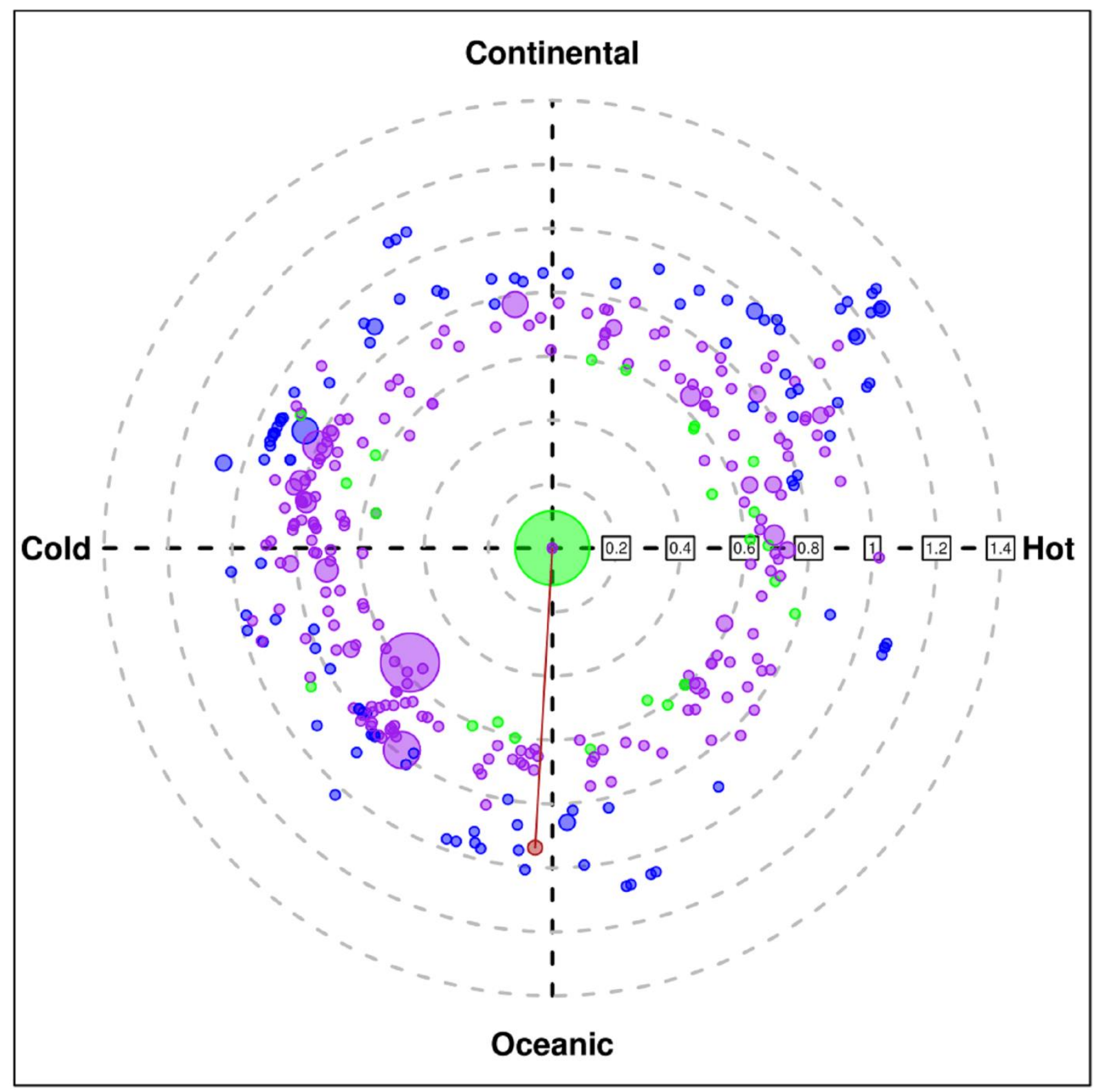

Figure 5. Position of host sites for plant translocations in the Western Palearctic on a climatic compass where all source sites have been grouped together at a single central point. The numbers on the dashed circles are the transformed climatic distances. The two axes are the principal axes of a principal component analysis performed on all data in seven bioclimatic variables in the Western 
Palearctic. The green circles correspond to translocations at a distance $<1 \mathrm{~km}$, the purple ones at distances between 1 and $25 \mathrm{~km}$, the blue ones at distances $>25 \mathrm{~km}$. The red line and circle symbolize a hypothetical translocation from Paris to London.
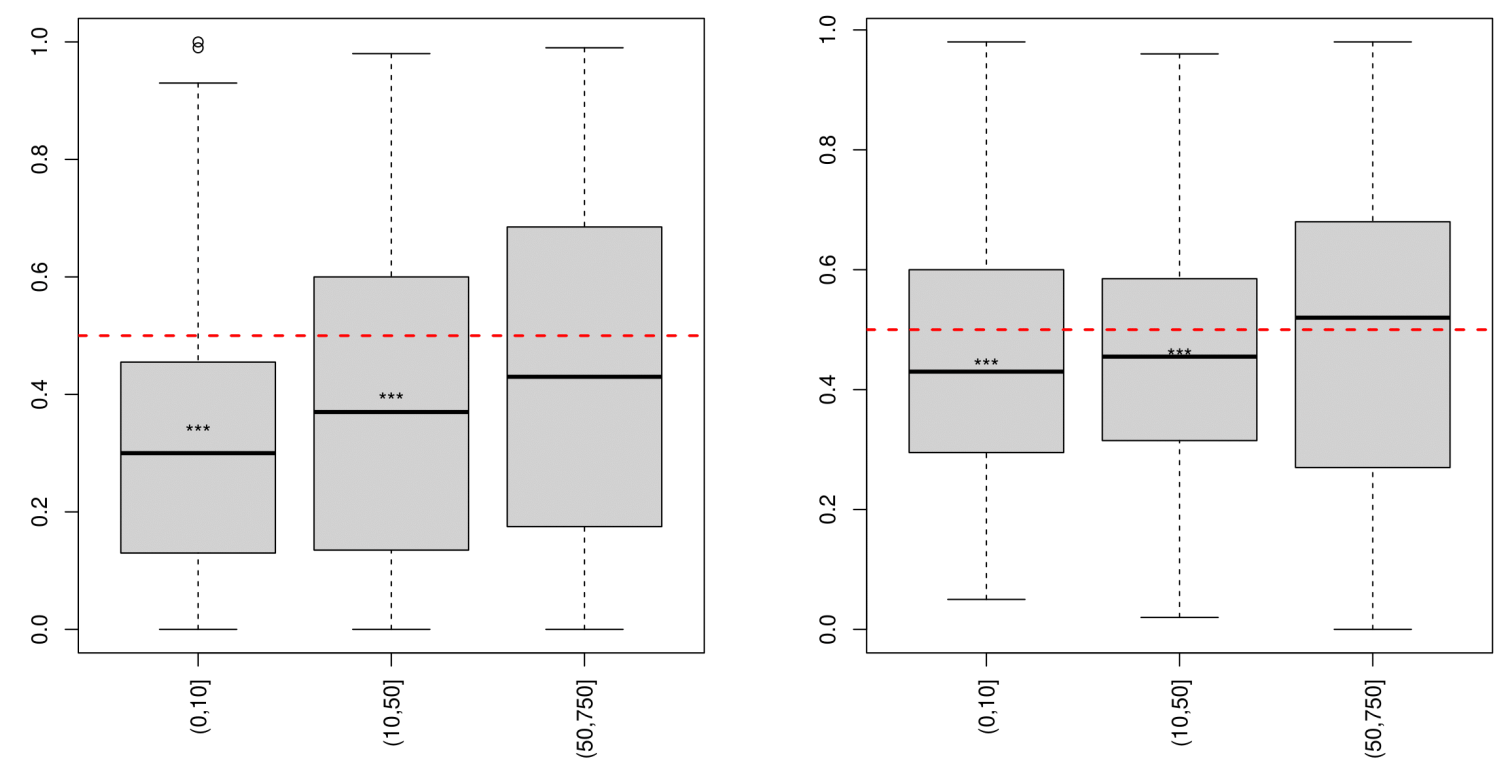

Figure 6. Boxplots showing the distributions of the percentages of simulated geographic points that have an Euclidian climatic distance to the source site lower than that of the true host site. Left: with random simulated points around the source site, at a distance equal to that where the host site is $\pm 5 \%$, in any direction. Right: with random simulated points around the chosen host site, in an area with a radius equal to 0.25 times the distance separating source and host sites. The $\mathrm{x}$ axis separates source-host pairs according the distance between them (in $\mathrm{km})$. *** indicates that the proportion of simulated geographic points with a lower climatic 
distance from the source site than the true host site was significantly less than $50 \%$ $(\mathrm{P}<0.001$, Student's t-tests $)$.
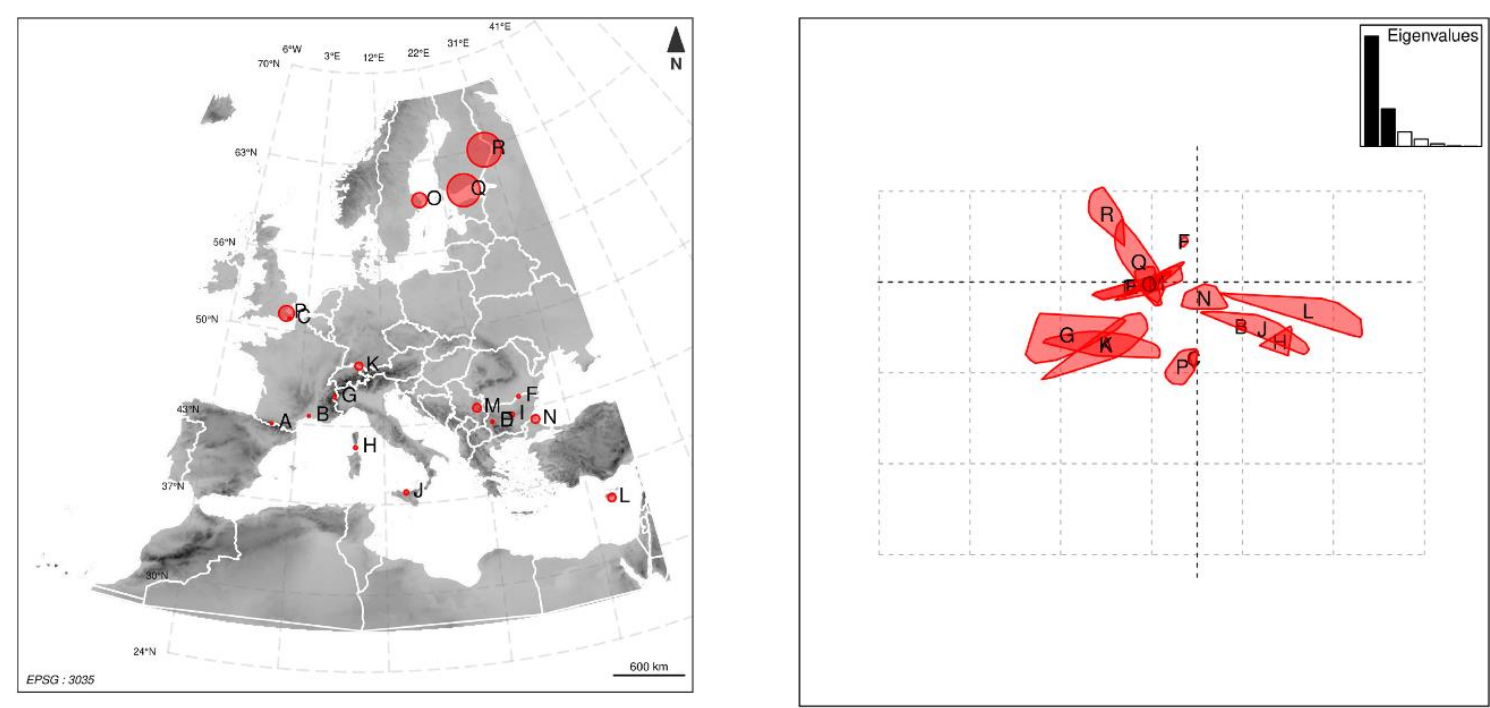

SuppInfo - Figure S1. Examples of sites that were excluded from the final dataset because the size of maximum possible errors resulting from uncertainty in site locations was too large. Left: Locations (labelled A to R) and buffers of geographic errors of 18 sites with a maximum possible error greater than $10 \mathrm{~km}$. Right: Locations and buffers of climatic errors of the same 18 sites in the climatic factorial space resulting from an PCA on 7 bioclimatic variables (see text). All pairs of sites that included one of these sites were excluded from the final dataset. 

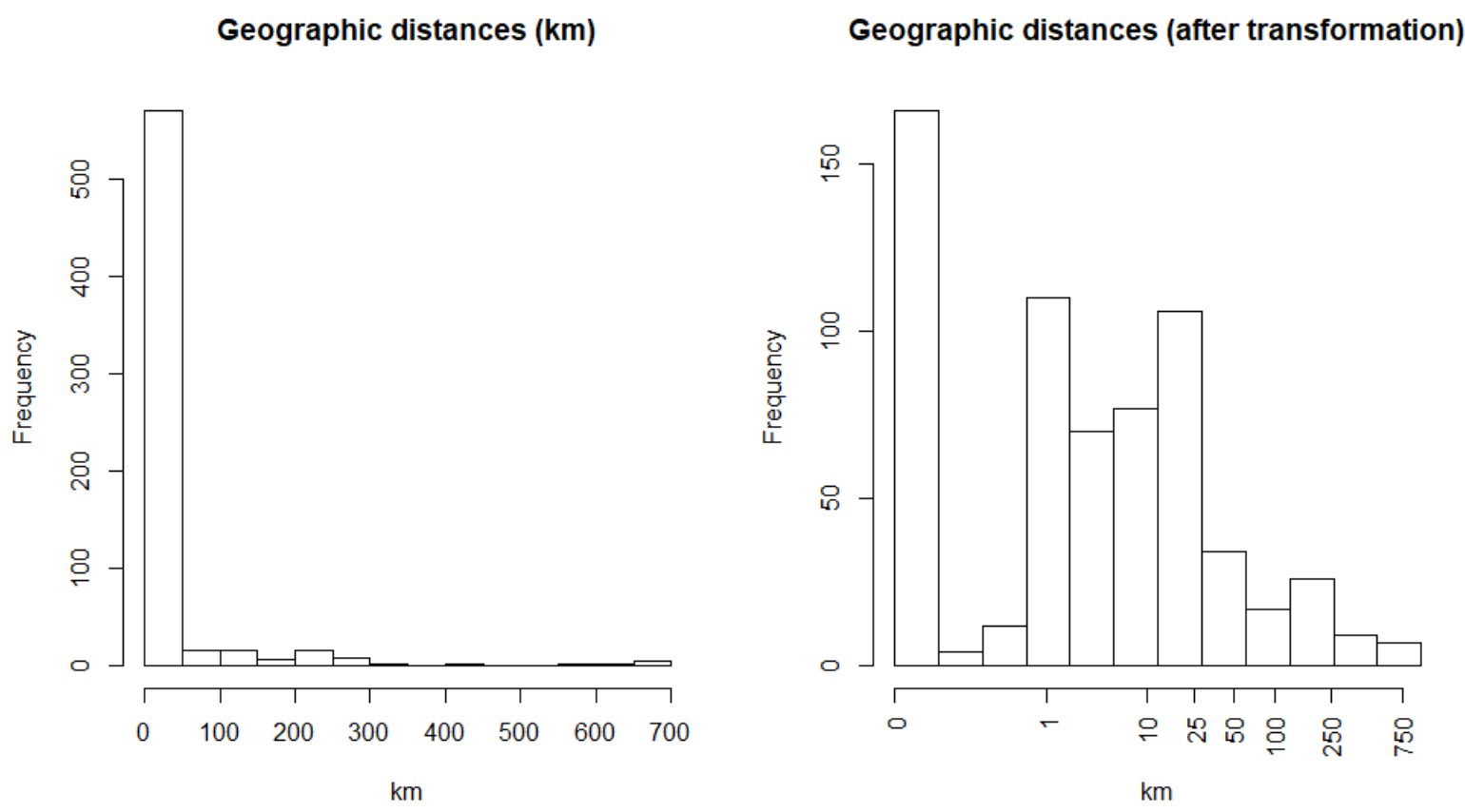

SuppInfo - Figure S3. Distribution of plant translocation distances in the Western Palearctic with untransformed data (left) and after the transformation $\left(x^{\prime}=\log \left(x^{1 / 3}+1\right)\right.$ (right) 